exceeding $0.5 \mathrm{mg} / \mathrm{kg}$ twice daily, do not cause a significant exacerbation or precipitation of tics in children with ADHD, when evaluated over a 1-year period and relying on parent and teacher reports. However, they caution that until the effect of MPH in larger samples has been studied, using more exact measures of tics, it would be wise to monitor for tics, especially if high doses of MPH are required.

By pooling data from treatment time periods (0-4, 4-8, and 8-12 months), and by using a statistical test amenable to small numbers, the authors were unable to demonstrate a significant difference in tic prevalence among $72 \mathrm{MPH}$-treated and 18 placebo patients. The clinical significance of the study may be questioned, however: 1) the control group was relatively small; 2) the severity of tics was different in the two groups (mainly severe in MPH-treated patients and 2 with Tourette's syndrome (TS), and none severe and none with TS in the placebo group; 3 ) lack of agreement between teacher and parent observations (only 5 of 27 cases with tics identified by both); 4) disparity in time of onset of tics in the two groups (most MPH-related tics developed within 4 months, whereas placebo-associated tics had an onset after 4 months). In fact, if one compares the cases with tics developing within 4 months (12 (60\%) of 20 in the MPH group cf to 1 (11\%) of 9 placebo cases), the conclusion might be different. The long duration of the study may have influenced variables (eg. caffeine intake, streptococcal infection, environmental stress), not considered as possible aggravating factors.

The relation between MPH and tics and TS is controversial. Some authors condone neurostimulant therapy for ADHD complicated by tics or TS, but only with parental informed consent (Zametkin AJ, Ernst M. N Engl J Med 1999;340:4046), whereas most favor avoidance of MPH in patients with a personal or family history of TS, and the use of conservative doses in treatment of ADHD (Millichap JG. Dev Med Child Neurol May 1999;41:356; Traverse L. Dev Med Child Neurol Dec 1998;40:847). Stimulant-induced tics are dose-related, a factor not addressed in the Law and Schachar, Toronto, study, occurring especially with larger doses - a $47 \%$ incidence with $0.5-1.3 \mathrm{mg} / \mathrm{kg}$ MPH (Borcherding BG et al. Psychiatry Res 1990;33:83-94; Tanner CM, Goldman SM. Neurol Clin 1997;15:395-402),

\title{
TOURETTE SYNDROME WITH GYRUS RECTUS CYSTS
}

Multicystic changes in the gyrus rectus of the left frontal lobe were demonstrated by brain magnetic resonance imaging in an 11-year-old boy with Tourette syndrome reported from Children's Regional Hospital at Cooper Hospital/University Medical Center, Camden, NJ. Symptoms and signs of comorbid ADHD or obsessive compulsive disorder were absent. Tics responded to low dose clonidine therapy. (McAbee GN, Wark JE, Manning A. Tourette syndrome associated with unilateral cystic changes in the gyrus rectus. Pediatr Neurol April 1999;20:322-324). (Respond: Dr McAbee, Division of Pediatric Neurology, Children's Regional Hospital, 3 Cooper Plaza, Suite 309, Camden, NJ 08103).

COMMENT. Neurobiologic studies of Tourette syndrome (TS) have previously demonstrated that the prefrontal and cingulate gyrus, midbrain, corpus callosum, limbic system, and thalamus may be involved in the pathophysiology of TS. The above case-report suggests that the gyrus rectus may also be implicated in TS, independent of the basal ganglia. (see Progress in Pediatric Neurology III, PNB Publ, 1997;pp321-323). 